\title{
Age at first concussion influences number of subsequent concussions
}

Julianne D. Schmidt, PhD, ATC ${ }^{\mathrm{a}, \mathrm{b}}$; Katherine Rizzone, MD, MPH ${ }^{\mathrm{c}}$; Nicole L. Hoffman, MS, ATC $^{\mathrm{a}, \mathrm{b}}$; Michelle L. Weber MS, ATC ${ }^{\mathrm{a}, \mathrm{b}}$; Courtney Jones, PhD MPH ${ }^{\mathrm{d}}$; Jeff Bazarian, MD, MPH ${ }^{\mathrm{d}}$; Steven P. Broglio, PhD, ATC ${ }^{\mathrm{e}}$, Michael McCrea, PhD, ABPP ${ }^{\mathrm{f}}$; Thomas W. McAllister, MD ${ }^{\mathrm{g}}$; on behalf of CARE Consortium Investigators*

\author{
Affiliations: \\ ${ }^{a}$ Department of Kinesiology; University of Georgia; 330 River Rd, Athens, GA 30606, USA \\ ${ }^{\mathrm{b}}$ UGA Concussion Research Laboratory; University of Georgia; 330 River Rd, Athens, GA \\ 30606, USA \\ ${ }^{\mathrm{c}}$ Department of Orthopedics; University of Rochester School of Medicine; 4901 Lac De Ville \\ Blvd, Rochester, NY 14618, USA \\ ${ }^{\mathrm{d}}$ Department of Emergency Medicine; University of Rochester School of Medicine; 265 \\ Crittenden Blvd, Box 655c, Rochester, NY 14642, USA \\ ${ }^{\mathrm{e}}$ University of Michigan Injury Center; University of Michigan; 401 Washtenaw Avenue, Ann \\ Arbor, Michigan 48109, USA \\ ${ }^{\mathrm{f}}$ Departments of Neurosurgery and Neurology; Medical College of Wisconsin; 8701 Watertown \\ Plank Road, Milwaukee, WI 53226, USA \\ ${ }^{\mathrm{g}}$ Department of Psychiatry; Indiana University School of Medicine; 355 W. 16th St., Suite 4800 \\ Indianapolis, IN. 46202, USA \\ * A complete list of non-author contributors appears in Appendix 1
}

\section{Corresponding Author:}

Julianne Schmidt, 330 River Rd, Athens GA 30602, t:(706)542-4388, f: (706)542-7649, [schmidtj@uga.edu]

\section{Author Emails:}

Katherine_Rizzone@urmc.rochester.edu

nhoffman25@uga.edu

michelle.weber25@uga.edu

Courtney_Jones@URMC.Rochester.edu

jeff_bazarian@urmc.rochester.edu

broglio@umich.edu

mmccrea@mcw.edu

twmcalli@iupui.edu

\section{Word Count: 2748}

Short Running Title: Age at first concussion

\section{Funding Source:}

This publication was made possible, in part, with support from the Grand Alliance Concussion Assessment, Research, and Education (CARE) Consortium, funded, in part by the National Collegiate Athletic Association (NCAA) and the Department of Defense (DOD). The U.S. Army Medical Research Acquisition Activity, 820 Chandler Street, Fort Detrick MD 21702-5014 is the 
awarding and administering acquisition office. This work was supported by the Office of the Assistant Secretary of Defense for Health Affairs through the Psychological Health and Traumatic Brain Injury Program under Award NO W81XWH-14-2-0151. Opinions, interpretations, conclusions and recommendations are those of the author and are not necessarily endorsed by the Department of Defense (DHP funds.)"

Conflict of Interest: The authorship team does not have any real or perceived conflicts of interest to report. The study sponsor did not influence the study design; the collection, analysis, and interpretation of data; the writing of the report; or the decision to submit the paper for publication. 


\section{Structured Abstract}

Background: Individuals that sustain their first concussion during childhood may be at greater risk for sustaining multiple concussions throughout their lifetime, due to a longer window of vulnerability. Purpose: To estimate the association between age at first concussion with number of subsequent concussions. Methods: A total of 23,582 collegiate athletes from 26 universities and military cadets from three military academies completed a concussion history questionnaire (65\% males, age: $19.9 \pm 1.4$ years). Participants self-reported concussions and age at time of each injury. Participants with a history of concussion $(n=3,647,15.5 \%)$ were categorized as having sustained their first concussion during childhood ( $<10$ years old - yo) or adolescence $(\geq 10$ yo \& $\leq 18$ yo). Poisson regression was used to model age group (childhood, adolescence) predicting number of subsequent concussions $(0,1,2+)$. A second Poisson regression was developed to determine whether age at first concussion predicted number of subsequent concussions. Results: Participants self-reporting their first concussion during childhood had an increased risk of sustaining subsequent concussions ( $R R=2.19,95 \%$ CI: $1.82,2.64$ ) compared to participants selfreporting their first concussion during adolescence. For every one-year increase in age at first concussion, we observed a $16 \%$ reduction in the risk of subsequent concussion $(\mathrm{RR}=0.84,95 \%$ CI:0.82,0.86). Conclusion(s): Individuals self-reporting a concussion at a young age sustained a higher number of concussions prior to the age of 18 . Concussion prevention, recognition, and reporting strategies are of particular need at the youth level.

Keywords: mild traumatic brain injury; head trauma, head injury; sport; youth injury 


\section{Introduction}

Concussion has become a major public health concern due to the emergence of research suggesting a possible link between injury and long-term emotional and cognitive consequences (1-4). Concerns regarding concussion span all levels of play and all sports, but youth athletes may be more vulnerable because they have an increased risk of injury $(3,5-8)$, a shortage of access to immediate medical provision (9), and may not be able to easily recognize the signs and symptoms of a concussion $(10,11)$. Many definitions of concussion exist, but the injury can be defined as "A change in brain function following a force to the head, which may be accompanied by temporary loss of consciousness, but is identified in awake individual with measures of neurological and cognitive dysfunction" (22).

As is true with many injuries, the strongest predictor of subsequent injury is a history of a previous injury (12). Concussive injury is no different as high school and college-aged athletes that sustain a concussion have an increased risk of sustaining a subsequent concussion (13-15). Schulz et al. (14) found that high school athletes with a history of one or more concussions were 2.25 times more likely to sustain a subsequent concussion compared to high school athletes without a history after adjusting for sports, body mass index, and year in school. Extrapolating these findings to youth athletes, Guskiewicz and Valovich McLeod (16) proposed that the longer the interval of time from first concussion to the end of the playing career, the greater the potential for sustaining multiple concussions (Figure 1). Theoretically, sustaining a concussion at a younger age may increase the duration of time (injury exposure) that an athlete participates in sport leading to a longer window of vulnerability to subsequent concussion. Therefore, athletes that sustain concussions during childhood may sustain an overall higher number of concussions, potentially causing prolonged recovery(17), early medical disqualification(17), and cumulative 
effects of multiple concussions(18-20). Yet, even with these multiple areas of concern, subsequent concussion risk in the child and young adolescent athlete is currently unknown, and the association between age group/age at first concussion with number of subsequent concussions has not been previously investigated.

The purpose of this study was to determine if age group (childhood v. adolescence) and age at first concussion influences number of subsequent concussions sustained prior to the age of 18. We hypothesized that individuals who self-report sustaining a first concussion during childhood would have a greater number of total concussions compared to those that sustained a first concussion in adolescence.

\section{Patients and Methods}

Data were collected via the Concussion Assessment, Research, and Education (CARE) Consortium study. Methods for the Consortium have previously been described in further detail (21). Each participant completed a baseline demographics questionnaire, symptom checklist, a mental status exam, a computerized neurocognitive assessment, and a balance assessment. For purposes of this study, data from the baseline demographics questionnaire were used to test our hypotheses.

\section{Participants}

The Consortium involved 26 universities and three military service academies. To be included in the CARE Consortium, participants had to be a rostered varsity student-athlete and/or a military cadet at one of the participating sites. Though the CARE Consortium does allow inclusion of minors (e.g. student-athlete starting college before 18), we excluded all participants under 18 years of age at time of consent $(n=148)$ to standardize an exposure window from ages 0-18 years across all participants. Demographics questionnaires were administered between July 
2013 and September 2016. All participants signed informed consent forms approved by each site's institutional review board and the United States Army Human Research Protection Office. Variable Definitions

Participants self-reported number of concussions experienced prior to college/university matriculation, the approximate dates of each injury, the age at time of each injury, whether each concussion was diagnosed or undiagnosed, and whether each concussion was sport or non-sport related. The following definition of concussion, endorsed by the 2014-15 National Collegiate Athletic Association Sports Medicine Handbook (22), appeared on the demographics packet: "A change in brain function following a force to the head, which may be accompanied by temporary loss of consciousness, but is identified in awake individuals with measures of neurological and cognitive dysfunction." The definition included a list of 12 common concussion symptoms and clarified that "A concussion can occur without being 'knocked out' or unconscious" and that “getting your 'bell rung' and 'clearing the cobwebs' is a concussion".

Participants with concussion histories were categorized as having sustained their first concussion either during childhood ( $<10$ years old - yo) or adolescence $(\geq 10$ yo $\& \leq 18$ yo) (23, 24). These age group categorizations are based on chronological age and not markers of biophysical development associated with passage from childhood to adolescence. We then determined the number of subsequent concussions sustained up until age 18. Participants were excluded from analyses if their reported age at time of injury and calculated age based on the reported date of injury differed by more than two years, or if the discrepancy could have placed them into a different categorization (childhood, adolescence) $(n=447,8.0 \%)$.

Statistical Analyses

Descriptive statistics were used to characterize the study sample. Poisson regression 
models were used to account for the count nature of subsequent concussions $(0,1,2+)$ and the possibility of multiple independent injuries in one participant. We first examined whether age group (childhood, adolescence) predicted the number of subsequent concussions $(0,1,2+)$. A separate Poisson model was developed to determine whether age at first concussion predicted the number of subsequent concussions. Unadjusted associations were estimated followed by multivariable adjusted models including the following covariates: sex, body mass index, and the number of sports that each participant participated in prior to college (as a proxy for exposure). We also conducted sensitivity analyses which stratified the sample by military status (varsity athletes, military cadet), contact level - as defined by the American Academy of Pediatrics (25) (contact/collision, limited-contact, non-contact), first concussion diagnosis status (diagnosed, not diagnosed), and first concussion sport-related status (sport-related, not sport related). Level of significance for all analyses was set $a$ priori at $\mathrm{p}<0.05$.

\section{Results}

The dataset included baseline demographics information for a total of 23,582 (15,232 males, 8,335 females, 15 missing) participants from 26 universities and three military academies. In total, 3,647 (15.5\%) of the sample self-reported at least one concussion prior to age 18 and met all inclusion criteria. Of the 3,647 participants, 267 (7.3\%) sustained their first concussion during childhood and 3,380 (92.7\%) sustained their first concussion during adolescence. Subsequent concussion history dispersion across groups is displayed in Table 1.

In unadjusted models, participants who self-reported sustaining their first concussion during childhood had roughly double the risk of a subsequent concussion ( $\mathrm{RR}=2.19,95 \% \mathrm{CI}: 1.82$, 2.64) compared to participants who self-reported their first concussion during adolescence (Table 2). Additionally, for every one-year increase in the age at which the first concussion was 
sustained, we observed a $16 \%$ reduction in the risk of subsequent concussion $(\mathrm{RR}=0.84,95 \% \mathrm{CI}$ : $0.82,0.86)$. Multivariate analyses that included sex, body mass index, and the number of sports prior to college revealed similar RR values for all models (Table 2).

Results for all univariate and multivariate sensitivity analyses are presented in Table 2. When stratified by military status, both varsity athletes $(n=2,822, \mathrm{RR}=2.34,95 \%$ CI: $1.92,2.89)$ and military cadets $(\mathrm{n}=825, \mathrm{RR}=1.76,95 \%$ CI: $1.13,2.73)$ who sustained their first concussion during childhood had a higher risk of sustaining a subsequent concussion, but the magnitude of the effect was more pronounced in the varsity athletes. When stratified by contact level, the effects of sustaining a concussion during childhood were more pronounced in contact/collision sport athletes $(n=1,773, R R=2.59,95 \% C I: 1.93,3.48)$ and limited-contact $(n=488, R R=2.70$, 95\% CI: $1.83,3.98)$ sports, but not significant in non-contact sports $(\mathrm{n}=556, \mathrm{RR}=1.53,95 \% \mathrm{CI}$ : 1.00, 2.34). Participants who self-reported sustaining their first concussion during childhood and had the injury diagnosed still had a greater risk of sustaining subsequent concussions $(n=2702$, $\mathrm{RR}=2.17,95 \% \mathrm{CI}: 1.72,2.74)$, but slightly less pronounced than those that did not have their first concussion diagnosed $(n=698, R R=2.68,95 \%$ CI: $1.55,4.63)$. Participants who self-reported sustaining their first concussion during childhood and that the injury occurred during sport still had a greater risk of sustaining subsequent concussions ( $n=2,835, R R=2.03,95 \%$ CI: 1.40, 2.95), but slightly less pronounced than those that sustained their first concussion outside of sport activity $(\mathrm{n}=567, \mathrm{RR}=2.39,95 \% \mathrm{CI}: 1.73,3.31)$.

\section{Discussion}

Our results indicate that college-aged athletes and military cadets who self-report sustaining their first concussion during childhood had a two-fold greater risk of sustaining subsequent concussions compared to those who self-reported sustaining their first concussion 
during adolescence. This study supports the body of literature indicating that prior concussion is an independent risk factor for subsequent concussion $(6,15,26)$, but expands by confirming the theory that the lengthened window of vulnerability to sustaining subsequent concussion results in a higher overall number of concussions prior to the age of 18 (16). This risk appeared to be amplified among varsity student-athletes, contact/collision and limited contact athletes, those whose first concussion went undiagnosed, and those whose first concussion occurred outside of sport. Sustaining a concussion at a younger age seemed to lengthen the interval of time that college athletes and military cadets participated in athletic activities with a greater susceptibility to concussion. The lengthened interval may mean that college athletes and military cadets that sustain a concussion at a young age are more likely to report to college with a history of multiple concussions.

Individuals who sustain a concussion at a young age may accumulate a greater overall number of concussions over their lifetime. Individuals with a history of concussion may either have a lower resistance to subsequent traumatic insults, or they may have intrinsic and extrinsic factors (e.g. sex, risk taking behavior, exposure to contact sport) that predispose them to sustaining subsequent concussions that are present prior to and following their first concussion (14). Though we included sex, body mass index, and number of sports played in the adjusted models, we did not have extensive control over events that occurred throughout the exposure period that might also influence concussion risk, such as duration of contact sport participation. However, we included the number of sports that each participant participated in prior to college into multivariate models as a proxy for exposure and found little effect (RR:1.04, 95\% CI: 1.01, 1.07 - Table 2).

Multiple Concussion 
Though the number of subsequent concussions was greater among those self-reporting their first concussion at a younger age, it is worth noting that a majority of participants never sustained a subsequent concussion (Table 1). However, $10.9 \%$ of participants that self-reported sustaining their first concussion during childhood had sustained a total of three concussions by the age of 18 , compared to just $3.9 \%$ in the adolescent group. A great deal of uncertainty remains regarding the consequences of sustaining multiple concussions. Previous research in this area has been limited to cross-sectional studies, has mostly focused on former professional football players with a wide range of comorbidities, and has not established causal relationships. However, a growing body of literature that has emerged over the past decade that proposes a potential link between a history of multiple concussions and risk of late life impairment. Professional football players reporting concussions have a greater risk for depressive episodes later in life compared with those retired players reporting no concussions (3). Retired professional football players reporting three or more previous concussions were three times more likely to be diagnosed with depression; those with a history of one or two previous concussions were 1.5 times more likely to be diagnosed with depression (2), and retired rugby players present with a dose increase on metrics of major depression with each reported concussion (5). Adolescents with a history of concussion also have a 3.3-fold greater risk for depression diagnosis (4). Spira et al.(8) reported that multiple lifetime concussions were associated with greater emotional distress, persistent post-concussive symptoms, and reduced attention. In addition to mood-related disorders, some studies have shown memory deficits (7) and higher prevalence of mild cognitive impairment (18) among retired athletes with a history of multiple concussion. More acutely, athletes sustaining subsequent concussions present with longer symptom resolution times, are kept out of play longer, and reported loss of consciousness more 
frequently than athletes sustaining new concussions (17). Though more research is needed to further elucidate the risk associated with multiple concussions, these preliminary studies raise concern that sustaining a greater number of lifetime concussions may trigger a cascade of neurological deterioration, warranting efforts to reduce the risk of accumulating a high number of concussions in a lifetime.

\section{Youth Concussion Prevention and Diagnosis}

Our findings highlight the need for focused efforts to improve concussion prevention and diagnosis efforts among youth. Most research aimed at concussion prevention has focused on high school and collegiate concussion risk with very few studies examining youth sport. Though concussion prevention is likely multifactorial, including a wide variety of intrinsic and extrinsic factors, preliminary evidence supports exploration of specific concussion prevention efforts such as player conditioning and rule changes. Some preliminary evidence suggests that neck strength among high school players may play a role in reducing concussion risk (29), but more research is needed to determine whether neck strengthening interventions effectively reduce concussion risk, especially in youth sport. Fair play ice hockey leagues, where teams receive season points for playing without excessive penalties, have been shown to reduce the frequency and severity of injuries sustained while playing hockey (30). Body contact, such as tackling in football or body checking in ice hockey, are often debated when discussing concussion prevention in youth sports. Though eliminating body contact from youth sports would likely decrease the risk of injury, more research is needed to determine whether players that are not exposed to body contact at a young age are at greater risk of injury once they later enter contact leagues. The medical community needs to commit more research efforts towards further identifying preventative factors and focus concussion prevention efforts across all levels of play, with 
special concern for youth sports. Feasible advancements in youth sport safety are needed in order to ensure that youth athletes reap the positive benefits of youth sport participation.

We report a slightly greater number and percentage of subsequent concussions among youth whose first concussion went undiagnosed. It is possible that medical provision received following concussion diagnosis might play a role in mitigating vulnerability to subsequent concussions. Immediate access to a health care provider trained in concussion recognition and management is typically sparse in youth sports (9). Concussed individuals that seek medical care may be managed more conservatively and held from sport. This is evidenced by the finding that youth athletes have 6.2 greater odds of returning to play within 24 hours compared to high school athletes (9). We also found that childhood concussions that were sustained while playing a sport were slightly less likely to result in subsequent concussion compared to those that occurred outside of sport. We lack detail on how non sport-related concussions occurred, but it is possible that the mechanisms of injury for childhood concussion (e.g. motor vehicle accident, fall on playground) result in a slightly greater risk for subsequent concussion.

There were limitations to our study. This was a retrospective, self-reported injury history using a demographics questionnaire developed by the CARE Consortium. Participants may not have been able to accurately recall the details of their prior concussions. We partially controlled for this by excluding participants that had discrepancies between the reported age and approximate date of the concussion. Information about events that occurred throughout the exposure period that might also influence concussion risk, such as duration of contact sport participation was not available. We used chronological age to establish age groups (childhood v adolescence). These periods are necessarily arbitrary and do not perfectly represent the actual biological and psychosocial changes associated with passage from childhood to adolescence. We 
did not have access to a good measure of duration of exposure to primary and secondary sports that would allow us to control for how long participants played or when participants first enrolled in certain high risk sports during youth. Risk factors that increased participants' injury risk may have been present both prior to, and following initial injury. Some youth athletes may be at greater risk of sustaining a concussion at a young age because they possess higher risk seeking behaviors (31) or have personal medical histories that predispose them to concussion. We lacked full control over all factors that might influence concussion risk. Future studies should consider determining how risk seeking behavior may modify risk of sustaining a concussion at a young age.

\section{Conclusions}

Individuals that sustained their first concussion during childhood had a two-fold greater risk of sustaining subsequent concussions compared to those who self-reported sustaining their first concussion during adolescence. Sustaining a concussion at a younger age increases the duration of time that an athlete participates in sport with a greater susceptibility to subsequent concussions. Feasible advancements in concussion prevention, recognition, and reporting at the youth sport level are needed. 
Acknowledgements: Acknowledgements: Contributing investigators include: Gerald McGinty, DPT, ATC, CSCS and Darren Campbell, Lt Col, USAF, MC, PCDR (United States Air Force Academy), Scott Pyne, MD (United States Naval Academy), John DiFiori, MD (University of California-Los Angeles), JT Eckner, MD (University of Michigan), Kevin M. Guskiewicz (University of North Carolina at Chapel Hill), PhD, ATC, Christina L. Master, MD, FAAP, CAQSM, MD and Kristy Arbogast, PhD (University of Pennsylvania), Steven Rowson, PhD, Ryan Tierney, PhD, ATC (Temple University), Stefan Duma, PhD and Joel Stitzel, PhD (Virginia Tech).

The authors would also like to thank Jody Harland, Janetta Matesan, Larry Riggen (Indiana University); Ashley Rettmann (University of Michigan); Melissa Koschnitzke (Medical College of Wisconsin); Michael Jarrett, Vibeke Brinck and Bianca Byrne (Quesgen); Thomas Dompier, Melissa Niceley Baker, and Sara Dalton (Datalys Center for Sports Injury Research and Prevention); and the research and medical staff at each of the participating sites. This publication was made possible, in part, with support from the Grand Alliance CARE Consortium, funded by the NCAA and the DoD. The USAMRAA, Ford Detrick, MD, USA, is the awarding and administering acquisition office. This work was supported by the Office of the Assistant Secretary of Defense for Health Affairs through the Psychological Health and Traumatic Brain Injury Program under Award No. W81XWH-14-2-0151. Opinions, interpretations, conclusions and recommendations are those of the authors and are not necessarily endorsed by the DoD (DHP funds).

\section{Appendix 1: Collaborators}

The following CARE Consortium members are non-author contributors:

April (Reed) Hoy MS, ATC, CSCS (Azusa Pacific University)

Joseph B. Hazzard, Jr. ATC (Bloomsburg University)

Louise A. Kelly, $\mathrm{PhD}$ (California Lutheran University)

Justus D. Ortega, $\mathrm{PhD}$ (Humboldt State University)

Nicholas Port, $\mathrm{PhD}$ (Indiana University)

Margot Putukian, MD., FACSM (Princeton University)

Dianne Langford, PhD (Temple University School of Medicine)

Patrick G. O'Donnell, MHA (U.S. Coast Guard Academy Regional Clinic)

Christopher C. Giza, MD, MS, CAQSM (University of California-Los Angeles)

Holly J. Benjamin, MD, FAAP, FACSM (University of Chicago)

Thomas Buckley, EdD, ATC (University of Delaware)

Thomas W. Kaminski, PhD, ATC, FNATA, FACSM, RFSA (University of Delaware)

James R. Clugston, MD, MS, CAQSM (University of Florida)

Luis A Feigenbaum, PT, DPT, ATC, LAT (University of Miami)

Jason P. Mihalik, PhD, ATC (University of North Carolina at Chapel Hill)

Jessica Dysart Miles, PhD, LAT, ATC (University of North Georgia)

Scott Anderson, ATC (University of Oklahoma)

Micky Collins, PhD (University of Pittsburgh Medical Center)

Anthony P. Kontos, PhD (University of Pittsburgh Medical Center) 
Sara Chrisman, MD, MPH (University of Washington)

Christopher M. Miles, MD (Dept of Family and Community Medicine)

Brian H. Dykhuizen, MS, ATC (Wilmington College)

M. Alison Brooks, MD MPH (University of Wisconsin)

Steven J. Svoboda, MD (United States Military Academy) 


\section{References}

1. Seal KH, Bertenthal D, Samuelson K et al. Association between mild traumatic brain injury and mental health problems and self-reported cognitive dysfunction in Iraq and Afghanistan Veterans. J Rehabil Res Dev; 2016; 53: 185-98.

2. Guskiewicz KM, Marshall SW, Bailes J et al. Recurrent concussion and risk of depression in retired professional football players. Med Sci Sports Exerc; 2007; 39: 9039.

3. Kerr ZY, Marshall SW, Harding HP, Jr., Guskiewicz KM. Nine-year risk of depression diagnosis increases with increasing self-reported concussions in retired professional football players. Am J Sports Med; 2012; 40: 2206-12.

4. Chrisman SPD, Richardson LP. Prevalence of diagnosed depression in adolescents with history of concussion. J Adolesc Health; 2014; 54: 582-6.

5. Decq P, Gault N, Blandeau M et al. Long-term consequences of recurrent sports concussion. Acta Neurochirurgica; 2016; 158: 289-300.

6. Guskiewicz KM, McCrea M, Marshall SW et al. Cumulative effects associated with recurrent concussion in collegiate football players: the NCAA Concussion Study. JAMA; 2003; 290: 2549-55.

7. Ford JH, Giovanello KS, Guskiewicz KM. Episodic Memory in Former Professional Football Players with a History of Concussion: An Event-Related Functional Neuroimaging Study. J Neurotrauma; 2013; 30: 1683-701.

8. Spira JL, Lathan CE, Bleiberg J, Tsao JW. The Impact of Multiple Concussions on Emotional Distress, Post-Concussive Symptoms, and Neurocognitive Functioning in 
Active Duty United States Marines Independent of Combat Exposure or Emotional Distress. J Neurotrauma; 2014; 31: 1823-34.

9. Kerr ZY, Zuckerman SL, Wasserman EB et al. Concussion Symptoms and Return to Play Time in Youth, High School, and College American Football Athletes. JAMA Pediatrics; 2016; 170: 647-53.

10. Miyashita TL, Diakogeorgiou E, Hellstrom B et al. High School Athletes' Perceptions of Concussion. Orthop J Sports Med; 2014; 2: 1-5.

11. Cusimano MD. Canadian minor hockey participants' knowledge about concussion. Can J Neurol Sci; 2009; 36: 315-20.

12. Kucera KL, Marshall SW, Kirkendall DT et al. Injury history as a risk factor for incident injury in youth soccer. Br J Sports Med; 2005; 39: 462-6.

13. Guskiewicz KM, Weaver NL, Padua DA, Garrett WE, Jr. Epidemiology of concussion in collegiate and high school football players. Am J Sports Med; 2000; 28: 643-50.

14. Schulz MR, Marshall SW, Mueller FO et al. Incidence and risk factors for concussion in high school athletes, North Carolina, 1996-1999. Am J Epidemiol; 2004; 160: 937-44.

15. Goodwin Gerberich S, Boen JR, Straub CP, Maxwell RE. Concussion Incidences and Severity in Secondary School Varsity Football Players. Am J Public Health; 1983; 73: 1370.

16. Guskiewicz KM, Valovich McLeod TC. Pediatric sports-related concussion. PM R; 2011; 3: 353-64.

17. Castile L, Collins CL, McIlvain NM, Comstock RD. The epidemiology of new versus recurrent sports concussions among high school athletes, 2005-2010. Br J Sports Med; 2012; 46: 603-10. 
18. Guskiewicz KM, Marshall SW, Bailes J et al. Association between recurrent concussion and late-life cognitive impairment in retired professional football players. Neurosurgery; 2005; 57: 719-26; discussion -26.

19. Slobounov S, Cao C, Sebastianelli W. Differential effect of first versus second concussive episodes on wavelet information quality of EEG. Clin Neurophysiol; 2009; 120: $862-7$.

20. Iverson GL, Gaetz M, Lovell MR, Collins MW. Cumulative effects of concussion in amateur athletes. Brain Injury; 2004; 18: 433-43.

21. Broglio S, McCrea M, McAllister T et al. A National Study on the Effects of Concussion in Collegiate Athletes and US Military Service Academy Members: The NCAA-DoD Concussion Assessment, Research and Education (CARE) Consortium Structure and Methods. Sports Medicine; 2017; 47: 1437-51.

22. 2014-15 NCAA Sports Medicine Handbook. 2014.

23. World Health O. Young People's Health, a Challenge For Society: Report of a Who Study Group On Young People; 1986. Report No.: 92-4-120731-0.

24. Age limits and adolescents. Paediatr Child Health; 2003; 8: 577-8.

25. Rice SG. Medical conditions affecting sports participation. Pediatrics; 2008; 121: 841-8.

26. Abrahams S, Mc Fie S, Patricios J et al. Risk factors for sports concussion: an evidencebased systematic review. British Journal of Sports Medicine; 2014; 48: 1-9.

27. Chassin L, Presson CC, Sherman SJ, Edwards DA. The natural history of cigarette smoking: Predicting young-adult smoking outcomes from adolescent smoking patterns. Health Psychology; 1990; 9: 701-16. 
28. Salam MT, Li Y-F, Langholz B, Gilliland FD. Early-Life Environmental Risk Factors for Asthma: Findings from the Children's Health Study. 2004:760.

29. Collins C, Fletcher E, Fields S et al. Neck Strength: A Protective Factor Reducing Risk for Concussion in High School Sports. Journal of Primary Prevention; 2014; 35: 30919.

30. Roberts WO, Brust JD, Leonard B, Hebert BJ. Fair-play rules and injury reduction in ice hockey. Archives Of Pediatrics \& Adolescent Medicine; 1996; 150: 140-5.

31. Morrongiello BA, Corbett M, McCourt M, Johnston N. Understanding Unintentional Injury Risk in Young Children II. The Contribution of Caregiver Supervision, Child Attributes, and Parent Attributes. J Pediatr Psychol; 2006; 31: 540-51.

\section{Legends for Figures}

Figure 1. Reproduced with permission from Guskiewicz and Valovich-McLeod 2011. Theoretically, sustaining a concussion at a younger age may increase the duration of time (injury exposure) that an athlete participates in sport leading to a longer window of vulnerability to subsequent concussion. Therefore, athletes that sustain concussions during childhood may sustain an overall higher number of concussions. 
Table 1. Frequencies and percentages of subsequent concussion history by childhood versus adolescence.

\begin{tabular}{|l|l|l|l|l|}
\hline & & $\begin{array}{c}\text { No subsequent } \\
\text { concussions }\end{array}$ & $\begin{array}{c}\text { 1 subsequent } \\
\text { concussion }\end{array}$ & $\begin{array}{c}\text { 2+ subsequent } \\
\text { concussions }\end{array}$ \\
\hline Age Group & & & \\
\hline Childhood & $\mathrm{n}=267$ & 165 & 73 & 29 \\
\hline & \% within group & 61.8 & 27.3 & 10.9 \\
\hline Adolescence & $\mathrm{n}=3380$ & 2755 & 494 & 131 \\
\hline & \%w within group & 81.5 & 14.6 & 3.9 \\
\hline
\end{tabular}

Table 2. Rate ratios and 95\% confidence intervals for unadjusted and adjusted age group at first concussion

\begin{tabular}{|c|c|c|c|c|}
\hline & $\begin{array}{c}\text { Unadjusted } \\
\text { RR }\end{array}$ & $95 \% \mathrm{CI}$ & $\begin{array}{l}\text { Multivariate- } \\
\text { adjusted RR* }\end{array}$ & $95 \% \mathrm{CI}$ \\
\hline \multicolumn{5}{|l|}{ Age Group } \\
\hline Childhood & 2.19 & $1.82,2.64$ & 2.21 & $1.84,2.66$ \\
\hline Adolescence & Reference & & Reference & \\
\hline \multicolumn{5}{|l|}{ Covariates } \\
\hline \multicolumn{5}{|l|}{ Sex } \\
\hline Male & & 1 & 0.73 & $0.63,0.84$ \\
\hline Female & & +2 & Reference & \\
\hline Body Mass Index & & 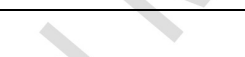 & 1.00 & $0.98,1.02$ \\
\hline \multirow[t]{3}{*}{ Number of Sports } & & 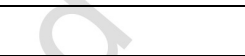 & 1.04 & $1.01,1.07$ \\
\hline & & 8 & & \\
\hline & & 3 & & \\
\hline \multicolumn{5}{|l|}{ Sensitivity analyses } \\
\hline Military Cadets & 1.76 & $1.13,2.73$ & 1.88 & $1.21,2.94$ \\
\hline Varsity Athletes & 2.34 & $1.92,2.89$ & 2.32 & $1.88,2.85$ \\
\hline Contact/Collision & 2.59 & $1.93,3.48$ & 2.60 & $1.93,3.50$ \\
\hline Limited-contact & 2.70 & $1.83,3.98$ & 2.80 & $1.89,4.16$ \\
\hline Non-contact & 1.53 & $1.00,2.34$ & 1.49 & $0.98,2.28$ \\
\hline Diagnosed & 2.17 & $1.72,2.74$ & 2.19 & $1.73,2.76$ \\
\hline Undiagnosed & 2.68 & $1.55,4.63$ & 2.71 & $1.57,4.69$ \\
\hline Sport-related & 2.03 & $1.40,2.95$ & 2.05 & $1.41,2.98$ \\
\hline Non sport-related & 2.39 & $1.73,3.31$ & 2.47 & $1.78,3.43$ \\
\hline
\end{tabular}

*Included sex, body mass index, and total number of sports played prior to college. 


\section{Recurrent and Cumulative \\ Concussion}

Collegiate Athlete

\begin{tabular}{lllllllllllllll}
\hline 8 & 9 & 10 & 11 & 12 & 13 & 14 & 15 & 16 & 17 & 18 & 19 & 20 & 21 & 22 \\
\hline
\end{tabular}

个

High

School

$\begin{array}{lllllllllllllll}8 & 9 & 10 & 11 & 12 & 13 & 14 & 15 & 16 & 17 & 18 & 19 & 20 & 21 & 22\end{array}$

Athlete

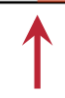

Pediatric Athlete

$$
\begin{array}{lllllllllllllll}
\hline 8 & 9 & 10 & 11 & 12 & 13 & 14 & 15 & 16 & 17 & 18 & 19 & 20 & 21 & 22 \\
\hline \uparrow & & & & & &
\end{array}
$$

YouthTimeline.tiff 